\title{
Modeling of Fuel Elements Cycling System in Pebble Bed Reactor Based on Timed Places Control Petri Nets*
}

\author{
Hongbing Liu ${ }^{1}$, Peng Shen ${ }^{1}$, Dong Du ${ }^{1}$, Xin Wang ${ }^{2}$, Haiquan Zhang ${ }^{2}$ \\ ${ }^{1}$ Department of Mechanical Engineering, Tsinghua University, Beijing, China \\ ${ }^{2}$ Institute of Nuclear and New Energy Technology, Tsinghua University, Beijing, China \\ Email: dudong@mail.tsinghua.edu.cn
}

Received January, 2013

\begin{abstract}
Pebble bed reactors use cycling scheme of spherical fuel elements relying on fuel elements cycling system (FECS). The structure and control logic of FECS are very complex. Each control link has strict requirements on time and sequence. This increases the difficulties of description and analysis. In this paper, timed places control Petri nets (TPCPN) is applied for the modeling of FECS. On this basis the simulation of two important processes, namely uploading fuel elements into the core for the first time and emptying the core is finished by simulation software Arena. The results show that as TPCPN is able to describe different kinds of logic relationship and has time properties and control properties, it's very suitable for the modeling and analysis of FECS.
\end{abstract}

Keywords: Timed Places Control Petri nets (TPCPN); Arena; Pebble Bed Reactors; Fuel Elements Cycling System (FECS)

\section{Introduction}

In recent years, the concept of the fourth generation of advanced nuclear energy systems is put forward in the world. Pebble bed HTGR is considered to be the preferred technology for the fourth generation of advanced nuclear energy systems $[1,2]$. Pebble bed reactors use cycling scheme of spherical fuel elements. Its running process can be summarized as following: spherical fuel elements are uploaded from the reactor core and transported in the near equal diameter pipeline; the burn-up measurement device measures the burn-up of the element; if the element has reached the target burn-up, or say it's a spent element, it will be transported to the spent elements tank; if not, the element will be lifted up to return to the core; new fuel elements with the same number of the spent elements will be uploaded into the core at the same time. The realization of the running relies on a very important support system of the reactor, namely fuel elements cycling system (FECS) [3]. The control logic of FECS is very complex. Each control link has strict requirements on time and sequence. So it's difficult to describe it with natural languages, flowcharts, etc.

Petri nets (PN) is a powerful graphical modeling tool. It has a strict mathematical basis as well as intuitive graphical expression. Relationship such as parallel, concurrent and conflict can be described very well with Petri

*Supported by the National S\&T Major Project (Grant No. ZX06901). nets [4]. Control Petri nets (CPN) can describe some easy control systems. Multi-level description of complex control systems can also be realized with the concepts of macro-place and macro-transition [5]. However, many control systems cannot be described with PN or CPN because the systems have requires on time.

In order to describe and analyze the control logic of FECS accurately, timed places control Petri nets (TPCPN) is used for the modeling of FECS. On this basis some simulations are done to analyze the operation process, including uploading fuel elements into the core for the first time and emptying the core. The results show that as TPCPN has the advantages on describing complex control system and contains time properties, it can describe the control logic of FECS very accurately. It also facilitates the simulation with software Arena.

\section{The Function of Fuel Elements Cycling System (FECS)}

The structure of FECS is very complex. The key features of FECS include uploading fuel elements into the core for the first time, the main cycling, uploading new fuel elements into the core, discharging the spent elements from the core and emptying the core.

When the system begins to run for the first time, hundreds of thousands of fuel elements will be uploaded into the core. This process is called uploading fuel elements into the core for the first time. During the period of the 
main cycling, fuel elements are uploaded from the core one by one and transported in the near equal diameter pipeline. Along the pipeline there are many kinds of devices including single conveyers, distribution devices, burn-up measurement devices, stop devices, etc. The elements which have reached the target burn-up are transported to the spent elements tank. The elements which have not reached the target burn-up are lifted in the lifting system for cycling (lifting system A) to return to the core. Some new fuel elements will be uploaded into the core at the same time. When there are special circumstances, hundreds of thousands of fuel elements in the core will be transported to the temporary storage system for spent elements (temporary storage system B) in succession. Then they will be transported through the lifting system for the spent elements (lifting system B) to the spent elements tank.

The reliable operation of FECS relies on a variety of devices and media, including more than 50 sets of delivery devices, more than 100 counters, nearly 200 electronic gauges, more than 1000 meters of pipeline, etc.

\section{The Timed Places Control Petri Nets Model of Fuel Elements Cycling System}

Considering the complex control logic of FECS, TPCPN can be used for its modeling.

\subsection{The Timed Places Control Petri Nets Model of the Head Control Room}

The head control room can control the operation of the subsystems, including inputting new fuel elements into the temporary storage system which is also called temporary storage system $\mathrm{A}\left(\mathrm{P}_{1}\right)$, transporting the fuel elements from temporary storage system $\mathrm{A}$ into the core $\left(\mathrm{P}_{3}\right)$, discharging the spent fuel elements $\left(\mathrm{P}_{4}\right)$, the main cycling $\left(\mathrm{P}_{6}\right)$ and emptying the core $\left(\mathrm{P}_{10}\right)$.

The TPCPN model of the head control room is shown in Figure 1. The relationship between the subsystems can be seen clearly from it, including parallel, concurrent, conflict and so on. For example, as both of $\mathrm{P}_{1}$ and $\mathrm{P}_{4}$ need to use the gas changing system, they cannot be carried out at the same time. In this case, an initial place

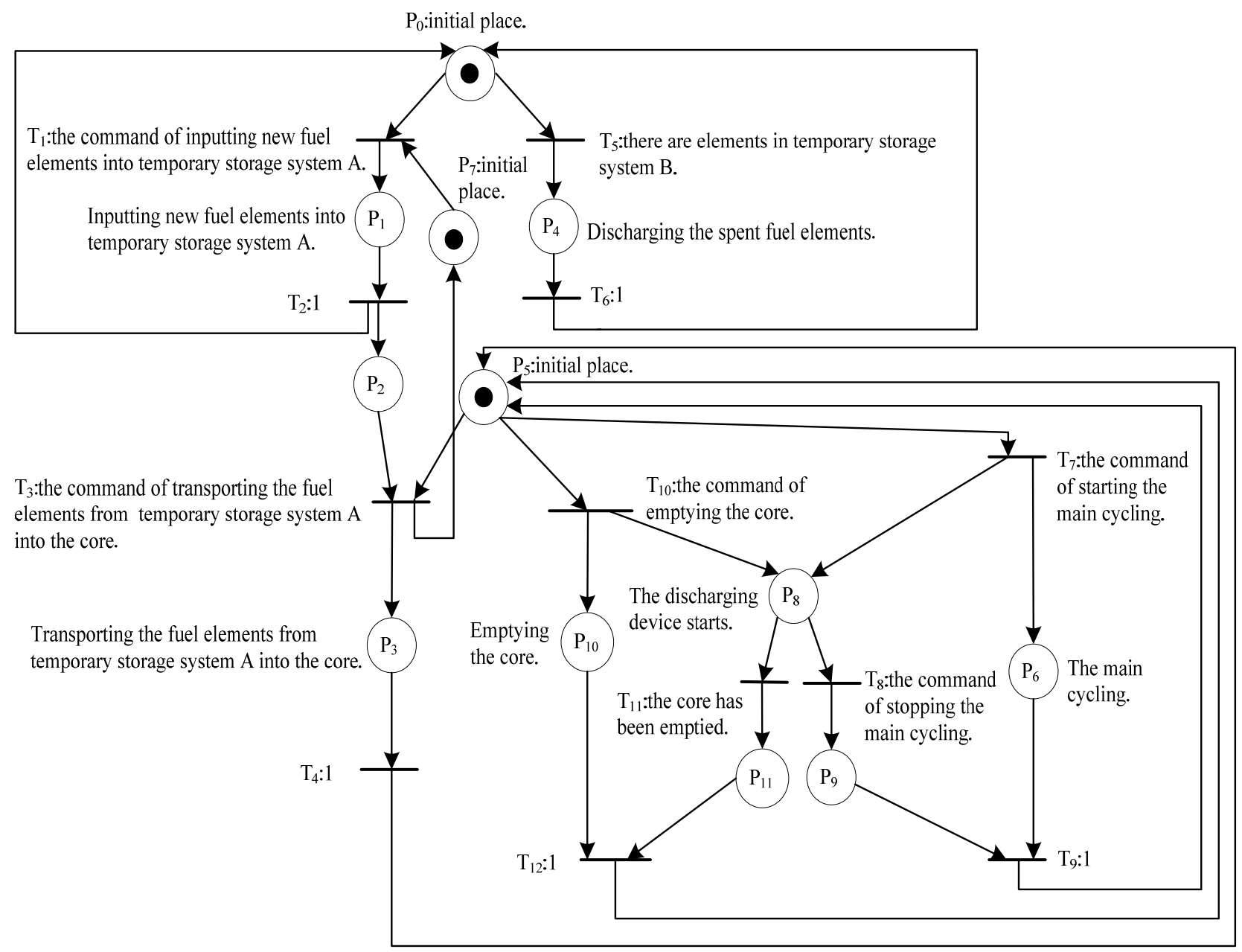

Figure 1. The TPCPN model of the head control room (TPCPN1). 


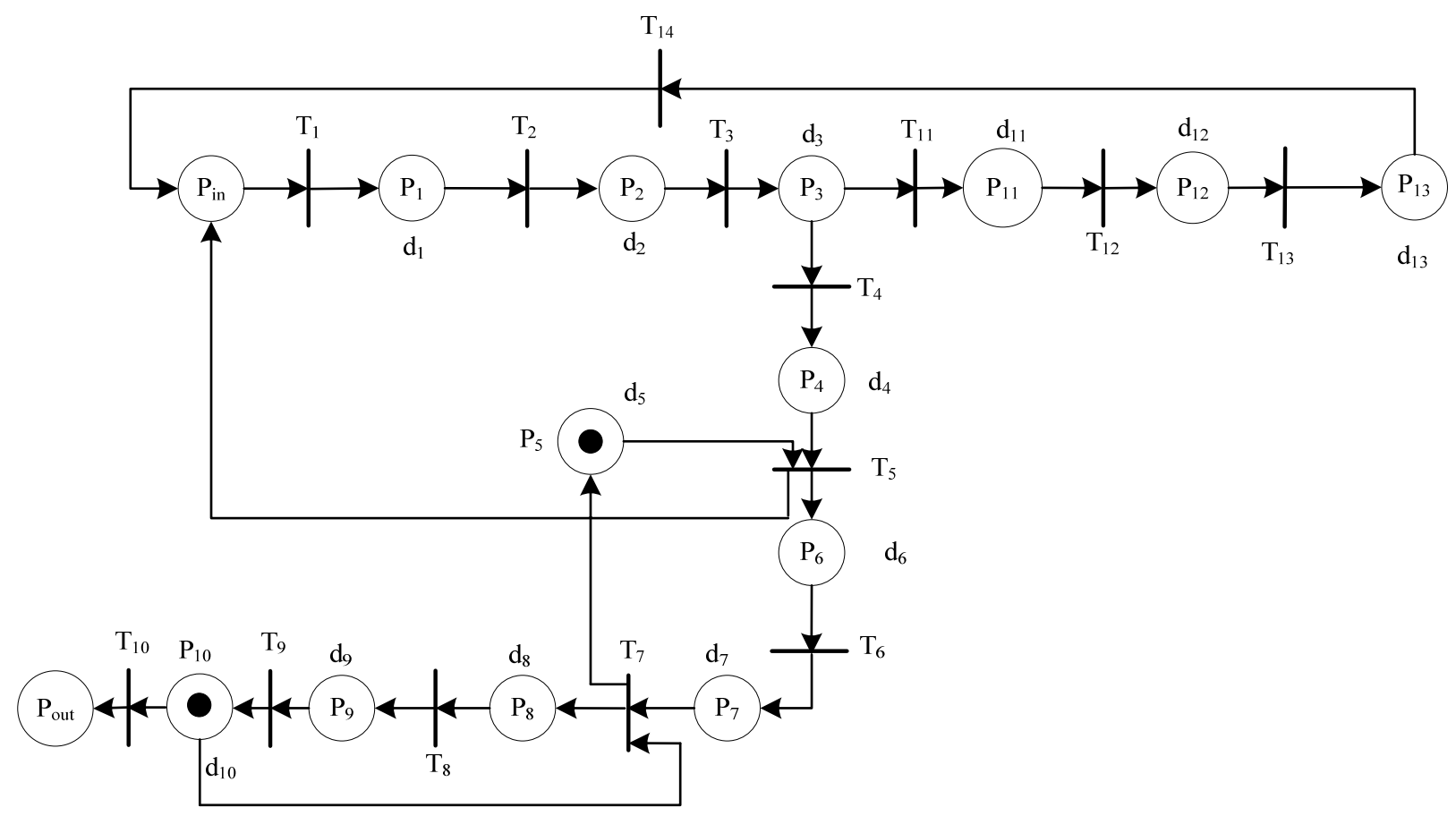

Figure 2. The TPCPN model of the main cycling (TPCPN2).

named $\mathrm{P}_{0}$ is used to avoid the two subsystems running simultaneously. Likewise, $\mathrm{P}_{5}$ can avoid $\mathrm{P}_{3}, \mathrm{P}_{6}$ and $\mathrm{P}_{10}$ running simultaneously.

\subsection{The Timed Places Control Petri Nets Model of the Main Cycling}

The TPCPN model of the main cycling is shown in Figure 2. When $\mathrm{P}_{6}$ in TPCPN1 gets a token, $\mathrm{P}_{\text {in }}$ is given a token. Then the main cycling starts. If there are fuel elements before the single conveyer $\left(T_{1}\right)$, one of the elements will be transported to the next section of the pipeline by the single conveyer $\left(\mathrm{P}_{1}\right)$. When counter A detects the signal of the element passing by $\left(\mathrm{T}_{2}\right)$, the burn-up measurement device begins to measure the burn-up of the element after a period of time $\left(\mathrm{P}_{2}, \mathrm{P}_{3}\right)$. If the element has not reached the target burn-up $\left(\mathrm{T}_{4}\right)$ and there are no elements in lifting system $\mathrm{A}\left(\mathrm{P}_{5}\right)$, the element will be transported to lifting system $A$ by the locator $\left(\mathrm{P}_{6}\right)$. When counter $\mathrm{B}$ detects the signal of the element passing by $\left(\mathrm{T}_{6}\right)$, the stop device will let the element into the core after a period of time $\left(\mathrm{P}_{7}, \mathrm{P}_{8}\right)$. Then the stop device returns to the former status $\left(\mathrm{P}_{9}\right)$. If the element has reached the target burn-up and there are no elements in temporary storage system $\mathrm{B}\left(\mathrm{T}_{11}\right)$, the distribution system will connect with temporary storage system $B\left(P_{11}\right)$. Then the element is transported to temporary storage system $\mathrm{B}\left(\mathrm{P}_{12}\right)$. When counter $\mathrm{C}$ detects the signal of the element passing by $\left(T_{13}\right)$, the distribution system will return to the former status to connect with lifting system $\mathrm{A}\left(\mathrm{P}_{13}\right)$. Then the judgment that whether there are elements before the single conveyer starts again.

When the command of stopping the main cycling is received, $\mathrm{T}_{8}$ in PN1 is fired. Then the discharge device is turned off. If there are no elements in the pipeline, $\mathrm{T}_{10}$ in PN2 is fired. $\mathrm{P}_{\text {out }}$ gets a token and gives out the signal that the main cycling is over.

The meanings of the places, transitions and time used in Figure 2 are listed in Table 1.

\subsection{The Other Timed Places Control Petri Nets Models}

The TPCPN models of the other processes are shown in Figures 3-6, including inputting the new fuel elements into temporary storage system $\mathrm{A}$, transporting the fuel elements from temporary storage system A into the core, discharging the spent fuel elements and emptying the core. The operation process will not be discussed in detail any more.

\section{The Simulation of Fuel Elements Cycling System with Arena}

Based on the TPCPN models of FECS, the simulation is conducted with the software Arena. Arena is widely used for system simulation. TPCPN models can be converted to Arena models very conveniently. Referring to the parameters given by reference [6], some input data for simulation are listed in Table 2. 
Table 1. The meanings of the places, transitions and time in TPCPN2.

\begin{tabular}{|c|c|c|c|c|c|}
\hline Place & Meaning & Time & Meaning & Transition & Meaning \\
\hline $\mathrm{P}_{1}$ & The single conveyor operates. & $\mathrm{d}_{1}$ & $\begin{array}{l}\text { The operation time of the single } \\
\text { conveyor. }\end{array}$ & $\mathrm{T}_{1}$ & $\begin{array}{l}\text { There are elements before the single } \\
\text { conveyor. }\end{array}$ \\
\hline $\mathrm{P}_{2}$ & Delay. & $\mathrm{d}_{2}$ & Delay. & $\mathrm{T}_{2}$ & $\begin{array}{l}\text { Counter A detects the signal of the } \\
\text { element passing by. }\end{array}$ \\
\hline $\mathrm{P}_{3}$ & The burn-up measure operates. & $\mathrm{d}_{3}$ & $\begin{array}{l}\text { The operation time of the burn-up } \\
\text { measure device. }\end{array}$ & $\mathrm{T}_{3}$ & Designed for sequence, $\mathrm{T}_{3}=1$. \\
\hline $\mathrm{P}_{4}$ & Designed for status. & $\mathrm{d}_{4}$ & Meaningless, $\mathrm{d}_{4}=0$. & $\mathrm{T}_{4}$ & $\begin{array}{l}\text { The element has not reached the target } \\
\text { burn-up. }\end{array}$ \\
\hline $\mathrm{P}_{6}$ & $\begin{array}{l}\text { The locator operates to transport } \\
\text { the element to lifting system A. }\end{array}$ & $\mathrm{d}_{6}$ & The operation time of the locator. & $\mathrm{T}_{6}$ & $\begin{array}{l}\text { Counter B detects the signal of the } \\
\text { element passing by. }\end{array}$ \\
\hline $\mathrm{P}_{7}$ & Delay. & $d_{7}$ & Delay. & $\mathrm{T}_{7}$ & Designed for sequence, $\mathrm{T}_{7}=1$. \\
\hline $\mathrm{P}_{8}$ & $\begin{array}{l}\text { The stop device transports the } \\
\text { element into the core. }\end{array}$ & $\mathrm{d}_{8}$ & The operation time of the stop device. & $\mathrm{T}_{8}$ & Designed for sequence, $\mathrm{T}_{8}=1$. \\
\hline $\mathrm{P}_{9}$ & $\begin{array}{l}\text { The stop device returns to the for- } \\
\text { mer status. }\end{array}$ & $\mathrm{d}_{9}$ & $\begin{array}{l}\text { The length of time for the stop } \\
\text { device to return to the former status. }\end{array}$ & $\mathrm{T}_{9}$ & Designed for sequence, $\mathrm{T}_{9}=1$. \\
\hline $\mathrm{P}_{11}$ & $\begin{array}{l}\text { The distribution system connects } \\
\text { with temporary storage system B. }\end{array}$ & $\mathrm{d}_{11}$ & $\begin{array}{l}\text { The length of time for the distribution } \\
\text { system to connect with temporary } \\
\text { storage system B. }\end{array}$ & $\mathrm{T}_{11}$ & $\begin{array}{l}\text { The element has reached the target } \\
\text { burn-up and there are no elements in } \\
\text { temporary storage system B. }\end{array}$ \\
\hline $\mathrm{P}_{12}$ & $\begin{array}{l}\text { The locator operates to transport the } \\
\text { element to temporary storage sys- } \\
\text { tem B. }\end{array}$ & $\mathrm{d}_{12}$ & The operation time of the locator. & $\mathrm{T}_{12}$ & Designed for sequence, $\mathrm{T}_{12}=1$. \\
\hline $\mathrm{P}_{13}$ & $\begin{array}{l}\text { The distribution system connects } \\
\text { with the lifting system for cycling. }\end{array}$ & $\mathrm{d}_{13}$ & $\begin{array}{l}\text { The length of time for the distribution } \\
\text { system to connect with lifting } \\
\text { system A. }\end{array}$ & $\mathrm{T}_{13}$ & $\begin{array}{l}\text { Counter } C \text { detects the signal of the } \\
\text { element passing by. }\end{array}$ \\
\hline- & - & - & - & $\mathrm{T}_{14}$ & Designed for sequence, $T_{14}=1$. \\
\hline
\end{tabular}

$\mathrm{T}_{1}$ :there are no elements in temporary storage system A.

$\mathrm{T}_{2}$ :new elements have been transported into temporary

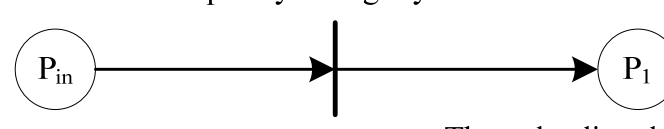

The uploading device starts.

$\mathrm{d}_{1}$ :time for uploading. storage system A.
The command of stopping the cycling is received and there are no elements

The element has reached the target burn-up and there are no elements in temporary storage system B.

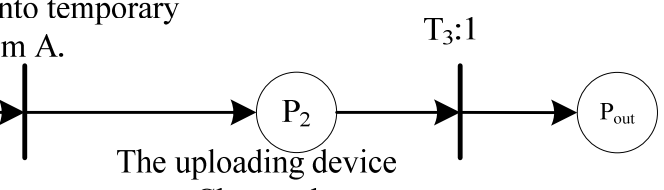
stops. Change the gas. $\mathrm{d}_{2}$ :time for changing the gas.

Figure 3. The TPCPN model of inputting the new fuel elements into temporary storage system A (TPCPN3). 


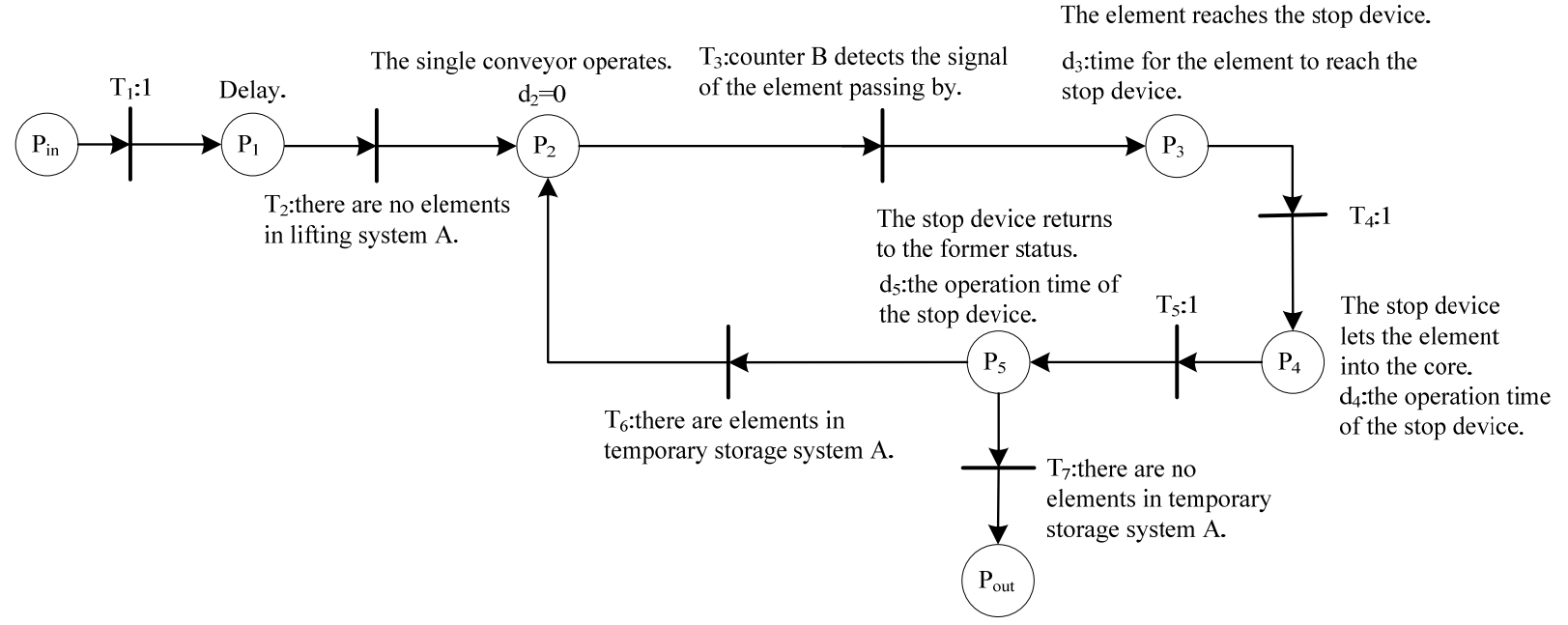

Figure 4. The TPCPN model of transporting the fuel elements from temporary storage system A into the core (TPCPN4).

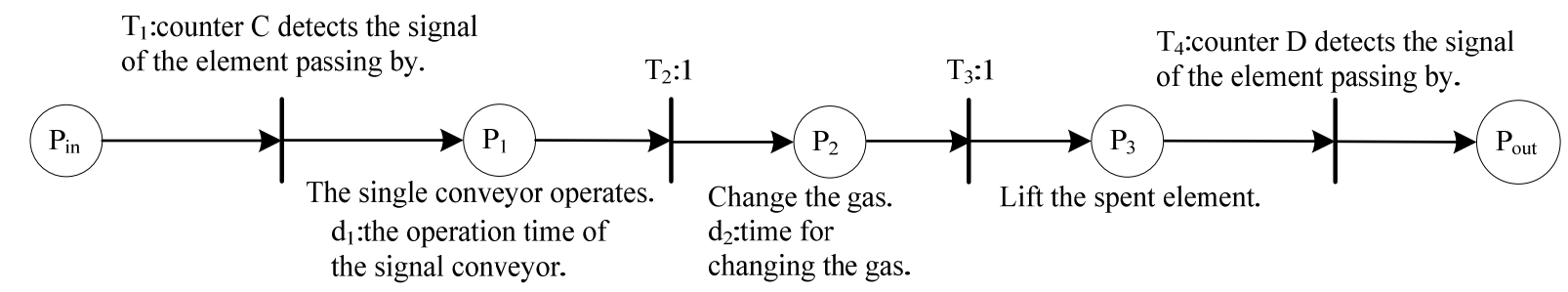

Figure 5. The TPCPN model of discharging the spent fuel elements (TPCPN5).

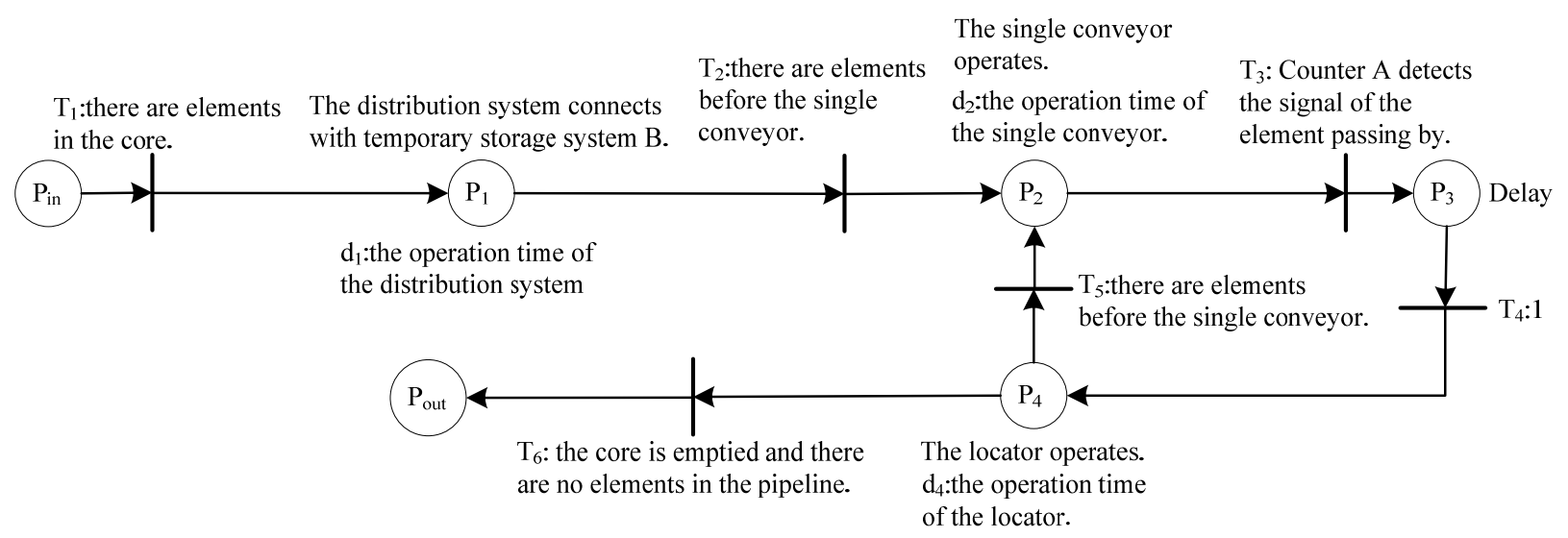

Figure 6. The TPCPN model of emptying the core (TPCPN6).

Table 2. Some input data for simulation.

\begin{tabular}{lcc}
\hline \multicolumn{1}{c}{ Data } & Unit & Value \\
\hline $\begin{array}{l}\text { The design capacity of temporary storage sys- } \\
\text { tem A. }\end{array}$ & & 100 \\
The length of time for the fuel element lifting in & $\mathrm{s}$ & 9.6 \\
lifting system A. & & \\
$\begin{array}{l}\text { The length of time for the fuel element lifting in } \\
\text { lifting system B. }\end{array}$ & $\mathrm{s}$ & 3.0 \\
The operation time of the delivery device. & $\mathrm{s}$ & 1.0 \\
\hline
\end{tabular}

\subsection{The Simulation of Uploading Fuel Elements into the Core for the First Time with Arena}

During this stage, 6 thousand to 12 thousand fuel elements will be uploaded into the core. The processes of inputting the new fuel elements into temporary storage system A and transporting the fuel elements from temporary storage system A into the core will be carried out. The gas needn't be changed.

Considering the capacity of temporary storage system A, a group of 100 fuel elements will be put into temporary storage system $\mathrm{A}$ at regular intervals. Then the ele- 
ments will be lifted in lifting system $\mathrm{A}$ and transported into the core.

The simulation result shows that if the time period between each two groups is $9 \mathrm{~min}$, the utilization rate of lifting system $\mathrm{A}$ is $80.07 \%$ while the utilization rate of temporary storage system $\mathrm{A}$ is as high as $92.22 \%$. In this case, it will take 14.70 hours to transport 10 thousand fuel elements into the core. If the task is 12 thousand elements, the time cost is 17.65 hours. The utilization rate of temporary storage system $A$ is so high that the speed of uploading fuel elements is limited.

In order to improve the speed of uploading and shorten the consuming time, a method called grouped tandem pneumatic lifting (GTPL) given by reference [7] can be used for the lifting process of the fuel elements. This method can realize several elements lifted together. The process of lifting is steady. Thus the lifting and transporting efficiency is much higher.

The task is to upload 10 thousand fuel elements into the core. If the maximum utilization rate of lifting system A is limited to below $90 \%$, the relationship between the number of elements lifted together and the time it costs to finish the task is listed in Table 3.

A conclusion can be got from Table 3 that as the number of elements lifted together increases, there is a marked decrease in the minimum time between each two groups. The time required to finish the task is reduced.

Table 3. The relationship between the number of elements lifted together and the time it costs to finish the task.

\begin{tabular}{ccc}
\hline $\begin{array}{c}\text { the number of } \\
\text { elements lifted } \\
\text { together }\end{array}$ & $\begin{array}{c}\text { the minimum time } \\
\text { period between each } \\
\text { two groups (min) }\end{array}$ & $\begin{array}{c}\text { the time it costs } \\
\text { to finish the task } \\
(\mathrm{h})\end{array}$ \\
\hline 1 & 9.3 & 15.50 \\
2 & 5.3 & 8.83 \\
3 & 4.0 & 6.67 \\
4 & 3.4 & 5.67 \\
5 & 2.9 & 4.83 \\
\hline
\end{tabular}

Table 4. The simulation result of emptying the core with GTPL.

\begin{tabular}{ccc}
\hline $\begin{array}{c}\text { the number of } \\
\text { elements lifted } \\
\text { together }\end{array}$ & $\begin{array}{c}\text { the maximum number of } \\
\text { uploading elements from } \\
\text { the core }\left(\mathrm{min}^{-1}\right)\end{array}$ & $\begin{array}{c}\text { the time it costs } \\
\text { to empty the core } \\
\text { (day) }\end{array}$ \\
\hline 1 & 9.6 & 43.40 \\
2 & 17.6 & 23.67 \\
3 & 24.5 & 17.01 \\
4 & 30.0 & 13.89 \\
5 & 35.3 & 11.80 \\
6 & 40.0 & 10.42 \\
\hline
\end{tabular}

The method can be used for uploading fuel elements into the core for the first time so that the task can be completed in a shorter time.

\subsection{The Simulation of Emptying the Core with Arena}

The process of emptying the core is simulated. The result shows that the process of lifting the spent elements has been the bottleneck as the burn-up measurement is cancelled. So the speed of emptying the core is limited by the process of lifting the spent elements.

In order to meet the requirements of the speed, the method of GTPL is used. The simulation result is shown in Table 4.

It can be seen from Table 4 that the maximum speed of uploading elements from the core increases as the number of elements lifted together increases. In this way the core can be emptied in a shorter time.

\section{Conclusions}

FECS of pebble bed reactors has very complex control logic. Every control link has very strict acquirements on time and sequence. TPCPN has time properties and control properties. It can describe the control logic accurately. So it's very suitable for the modeling of FECS. In addition the simulation of FECS can be conducted to analyze the control logic. This provides the basis for the design optimization of reactors.

\section{REFERENCES}

[1] Z. X. Wu and Z. Y. Zhang, "World Development of Nuclear Power System and High Temperature Gas-cooled Reactor," Chinese Journal of Nuclear Science and Engineering, 2000(3), pp. 211-219.

[2] Z. Y. Zhang, Z. X. Wu, D. Z. Wang, et al., "Current Status and Technical Description of Chinese $2 \times 250$ MWth HTR-PM Demonstration Plant,” Nuclear Engineering and Design, Vol. 239, No. 7, 2009, pp. 1212-1219. doi:10.1016/j.nucengdes.2009.02.023

[3] P. Shen, D. Du, G. L. Guo, et al., "Research on Pneumatic Transportation of Fuel Elements in Pebble Bed Reactor," Power and Energy Engineering Conference (APPEEC), Shanghai, China, 2012.

[4] T. Murata, "Petri Nets - Properties, Analysis and Applications," Proceedings of the IEEE, Vol. 77, No. 4, 1989, pp. 541-580. doi:10.1109/5.24143

[5] Z. D. Han, J. G. Liu and S. Luo Sheng, "Design Method of Control System for HTGR Fuel Handling Process with Control Petri Net,” Nuclear Power Engineering, Vol. 29, No. 1, 2008, pp. 14-18.

[6] P. Shen, K. Zeng, Du Dong, et al., "Dynamic Modeling and Application of Pneumatic Near-diameter Spheres in Pipeline Transportation in A Pebble Bed Reactor," Qinghua Daxue Xuebao, Vol. 52, No. 8, 2012, pp. 
1075-1080.

[7] P. Shen, D. Du, H. B. Liu, et al., "A Method of Grouped Tandem Fuel Elements of Pneumatic Transportation in
Pebble Bed Reactor," CHN Patent No. CN201210227180.8, 2012. 